\title{
SIMS Depth Profiling of Polymer Surfaces
}

\author{
Riichirô CHÛJô \\ Department of Biomolecular Engineering, Tokyo Institute of Technology, \\ 12-1 Ookayama 2-chome, Meguro-ku, Tokyo 152, Japan
}

(Received November'26, 1990)

\begin{abstract}
Concentration gradient was found in surface-fluorinated polyolefin films from SIMS depth profilings. Results were analyzed with a one-dimensional diffusion equation modified by the effect of chemical reaction. Similar gradients were found in the blends of poly(vinylidene fluoride) and poly (methyl methacrylate), the polymer optical fibers, and video tapes.

KEY WORDS Depth Profiling/Concentration Gradient/ SIMS / Diffusion equation / Surface Tension / Fluorinated Polyolefin / Polymer Blend/Optical Fiber / Video Tape
\end{abstract}

Concentration gradient in polymeric material is becoming one of the most important factors in the molecular design of them. SIMS (Secondary Ion Mass spectrometry) is applicable to the depth profiling of polymeric materials; this technique is quite promising to obtain the information on the concentration gradient. ${ }^{1-3}$ SIMS is more advantageous than the other methods such as XPS (X-ray Photoelectron Spectroscopy) in two points; 1) the maximum of detectable depth in XPS is limited to $5 \mathrm{~nm}$ due to the finite escape depth of photo electron, while there is no limit in SIMS, and 2) the information is obtained for any individual depth in SIMS (differentiated form), while it is obtained in the integral form from the surface to the desired depth in XPS. There is, of course, disadvantage in SIMS than in XPS; XPS depth profiling 
can be done nondestructively, while SIMS one is destructive. Nevertheless, SIMS is, as a whole, more advantageous than XPS. In this paper, results from our studies on SIMS depth profiling will be surveyed; they are applications to surfacefluorinated polyolefin films, polymer blends, optical fibers, and video tapes.

\section{EXPERIMENTAL}

SIMS was observed with a model A-DIDA-3000 equipped by Atomika Technische Physik GmbH. The primary $\mathrm{Ar}^{+}$ion beam was accelerated with a voltage of $3 \mathrm{kV}$ and its beam current was $50 \mathrm{~mA}$. Such a low current is effective to prevent from any change (thermal or chemical) of the sample surface. Furthermore, the sample was covered by an electron shower compensating for the charge-up. During measurements the pressure was kept at $3 \times 10^{-9}$ torr.

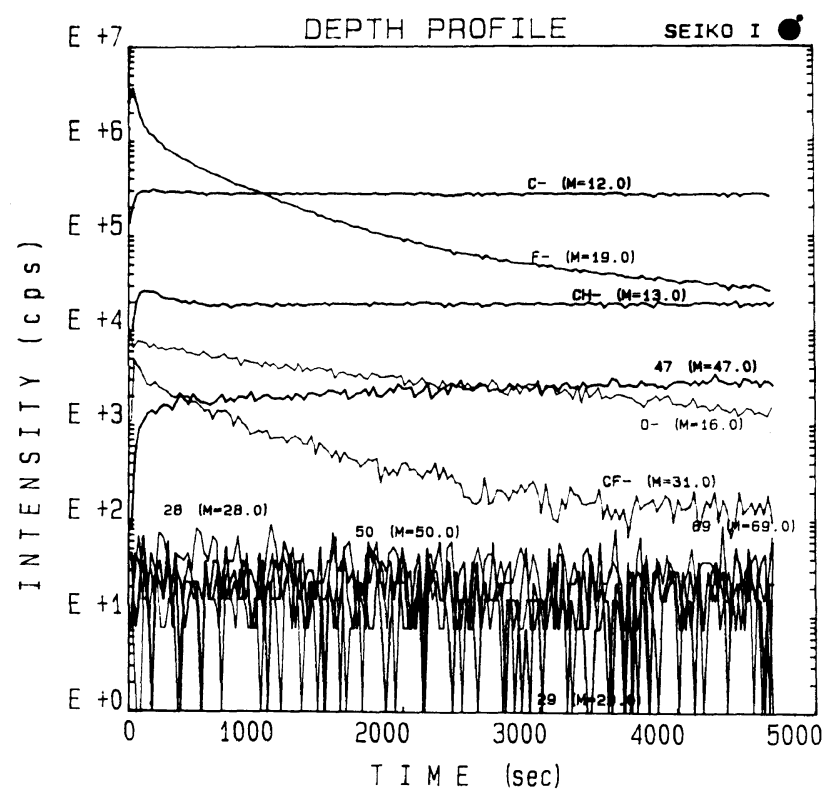

Figure 1. Depth profiling of surface-fluorinated polyethylene which contains fluorine atoms of $9.0 \mu \mathrm{g} \mathrm{cm}{ }^{-2}$. 


\section{RESULTS AND DISCUSSION}

\section{SURFACE-FLUORINATED POLYOLEFIN FILMS}

Surface fluorination of polyethylene accomplished by the contact with fluorine gas is rather old technology which was proposed in 1954.4 Enthalpy balance of this reaction is given by ${ }^{5}$

$$
\begin{array}{cl}
\mathrm{F}_{2} \rightarrow 2 \mathrm{~F}^{\cdot} & \Delta \mathrm{H}=+154 \mathrm{~kJ} \mathrm{~mol}^{-1} \\
\mathrm{~F}+-\mathrm{CH}_{2}-\mathrm{CH}_{2}-\rightarrow-\dot{\mathrm{C}} \mathrm{H}-\mathrm{CH}_{2}-+\mathrm{HF} & \Delta \mathrm{H}=-142 \mathrm{~kJ} \mathrm{~mol}^{-1} \\
\mathrm{~F}_{2}+-\dot{\mathrm{CH}}-\mathrm{CH}_{2}-\rightarrow-\mathrm{CHF}-\mathrm{CH}_{2}-+\mathrm{F} & \Delta \mathrm{H}=-285 \mathrm{~kJ} \mathrm{~mol}^{-1}
\end{array}
$$

Therefore, if a fluorine molecule is dissociated into two fluorine radicals, succeeding reactions proceeds automatically. This technology is very simple. Nevertheless, this technique is considerably new in practical application ${ }^{6}$. For instance, the effectiveness of fluorination was found in high density polyethylene (HDPE) gasoline container; gasoline packaged in an untreated HDPE container and kept at $50^{\circ} \mathrm{C}$ rapidly diffuses and evaporates through the container wall, losing over half its weight in less than 4 weeks. When packaged in fluorinated HDPE containers, gasoline permeation becomes virtually negligible. In order to characterize the surface-fluorinated polyethylenes, SIMS depth profiling was done making use of the intensities of intense secondary anions whose mass numbers are $12,13,16,19,31,47,50$, and $69 .{ }^{7}$ The anion of $\mathrm{m}=16$ was observed for the convenience of oxygen effect. Remaining anions are assigned to $\mathrm{C}^{-}, \mathrm{CH}^{-}$, $\mathrm{F}^{-}, \mathrm{CF}^{-}, \mathrm{COF}^{-}, \mathrm{CF}_{2}^{-}$, and $\mathrm{CF}_{3}^{-}$in the order of increasing mass numbers. Anions of $\mathrm{m}=28$ and 29 were also intense. However, they are not assigned to $\mathrm{C}_{2} \mathrm{H}_{4}{ }^{-}$nor $\mathrm{C}_{2} \mathrm{H}_{5}{ }^{-}$, but ${ }^{28} \mathrm{Si}^{-}$and ${ }^{29} \mathrm{Si}^{-}$due to the traces of contamination. In Figure 1 is shown the profiling of a sample which contains fluorine atoms of $9.0 \mu \mathrm{g} \mathrm{cm} \mathrm{cm}^{-2}$.

The diffusion equation in one-dimensional system is given by

$$
\frac{\partial C}{\partial t}=D \frac{\partial^{2} C}{\partial x^{2}}
$$


where $x, t$, and $c$ stand coordinate, time, and the concentration of substance, respectively. D is the diffusion coefficient which is assumed to be independent of the concentration. If the diffusion is accompanied by chemical reaction, Eq (2) is modified as follows:

$$
\frac{\partial C}{\partial t}=D \frac{\partial^{2} C}{\partial x^{2}}-\frac{\partial S}{\partial t}
$$

where $S$ is the concentration of immobilized solute. In the reaction (1) the concentration of $-\mathrm{CHF}$ - is given by

$$
\frac{\mathrm{d}(-\mathrm{CHF}-)}{\mathrm{at}}=\mathrm{k}_{2}\left(\mathrm{~F}_{2}\right)(-\dot{\mathrm{C}} \mathrm{H}-)
$$

where $\mathrm{k}_{2}$ is the rate constant in the third stage of the reaction (1). In stationary state, (- $\dot{C} H-)$ should be constant. Eq (4) is, therefore, simplified into

$$
\frac{\mathrm{d}(-\mathrm{CHF}-)}{\mathrm{at}}=\mathrm{k}\left(\mathrm{F}_{2}\right)
$$

where $\mathrm{k}$ is equal to the product of $\mathrm{k}_{2}$ and $\left(\mathrm{F}_{2}\right)$. The quantities $(-\mathrm{CHF}-)$ and $\left(\mathrm{F}_{2}\right)$ in $\mathrm{Eq}(5)$ correspond to $S$ and $C$, respectively, in Eq (3). Eq (3) is, therefore, simplified into

$$
\frac{\partial C}{\partial t}=D \frac{\partial^{2} C}{\partial x^{2}}-k C
$$

This equation has been used to describe the dyeing process by reactive dyestaffs, and this can be used to describe the reaction (1) without any modification. In our case, the initial condition

$$
t=0, \quad x>0 . \quad C=0
$$

and the boundary conditions

$$
\begin{array}{ll}
t>0, & x=0, \quad c=C_{0} \\
t>0, & x \rightarrow \infty, \quad c=0
\end{array}
$$

are practical, because the reaction was done for polyethylene film by the contact with fluorine-containing gas. The analytical solution of Eq (6) under the conditions of Eq (7) and $(8)$ is obtained as follows ${ }^{8}$ :

$$
\begin{aligned}
& C=\frac{C_{0}}{2}\{\exp (-x \sqrt{k / D}) \operatorname{erfc}((x / 2 \sqrt{D t})-\sqrt{k t}) \\
& +\exp (x \sqrt{k / D}) \operatorname{erfc}((x / 2 \sqrt{D t})+\sqrt{k t})\}
\end{aligned}
$$


where erfc(z) is the coerror function of error function, erf $(z)$ and is given by

$$
\operatorname{erfc}(z)=1-\operatorname{erf}(z)=(2 / \sqrt{\pi}) \int_{z}^{\infty} \exp \left(-\xi^{2}\right) d \xi
$$

The quantity, $s(t)$, is, therefore, given by

$$
\begin{aligned}
S & =\int_{0}^{t} k C d t \\
& =(k C o / 2\{(t-(x / 2 \sqrt{D k})) \exp (-x \sqrt{k / D}) \operatorname{erfc}((x / 2 \sqrt{D t})-\sqrt{k t}) \\
& +(t+(x / 2 \sqrt{D k})) \exp (x \sqrt{k / D}) \operatorname{erfc}((x / \sqrt{2 D t}+\sqrt{k t})\}
\end{aligned}
$$

In depth profilings, the ordinate is the intensity, I, of secondary ion, and the abscissa is the time, $\tau$, for measurement. Therefore, if proportionalities

$$
\begin{aligned}
& I=\lambda S \\
& \tau=\mu \mathrm{x}
\end{aligned}
$$

hold, Eq (11) can be written as

$$
\begin{aligned}
I & =(k \lambda C o / 2)\{(t-(\tau / 2 \mu \sqrt{\mathrm{Dk}})) \exp (-\tau \sqrt{\mathrm{kt}} / \mu \sqrt{\mathrm{Dt}}) \\
& x \operatorname{erfc}((\tau / 2 \mu \sqrt{\mathrm{DE}})-\sqrt{\mathrm{kt}})+(t+(\tau / 2 \mu \sqrt{\mathrm{Dk}})) \\
& x \exp (\tau \sqrt{\mathrm{kt}} / \mu \sqrt{\mathrm{Dt}}) \operatorname{erfc}((\tau / 2 \mu \sqrt{\mathrm{Dt}})+\sqrt{\mathrm{kt}})\}
\end{aligned}
$$

In each depth profiling, the behavior in very small $\tau$ cannot be analyzed by Eq (13) due to rather complicated phenomena in surface region, and the behavior in very large $\tau$ cannot also due to insufficient memory size of computer in less intense region. Eq (13) is, therefore, used to analyze the depth profiling pattern in intermediate $\tau$ values. Results are tabulated in Table I. Contents of fluorine atoms determined Table I. Parameters for surface-fluorinated Polyethylene

$\begin{array}{rcccc}\text { Sample } & \begin{array}{c}\text { Fluorine } \\ \text { Contents } / \mu \mathrm{g} \mathrm{Cm}^{-2}\end{array} & \mathrm{k} \lambda \mathrm{C}_{0} \mathrm{t} / 10^{6} & \mu \sqrt{\mathrm{Dt}} / 10^{3} & \sqrt{\mathrm{kt}} \\ \mathrm{E} & 4.6 & 1.03 & 2.12 & 1.02 \\ \mathrm{~F} & 61.3 & 3.97 & 1.73 & 1.04 \\ \mathrm{G} & 64.2 & 2.57 & 0.45 & 2.27 \\ \mathrm{H} & 88.2 & 2.77 & 1.66 & 1.30 \\ \mathrm{I} & 150.2 & 2.08 & 1.56 & 0.99\end{array}$

from fluorescent $x$-ray analysis are also tabulated in the Table.

\section{POLYMER BLENDS}


Poly(vinylidene fluoride)

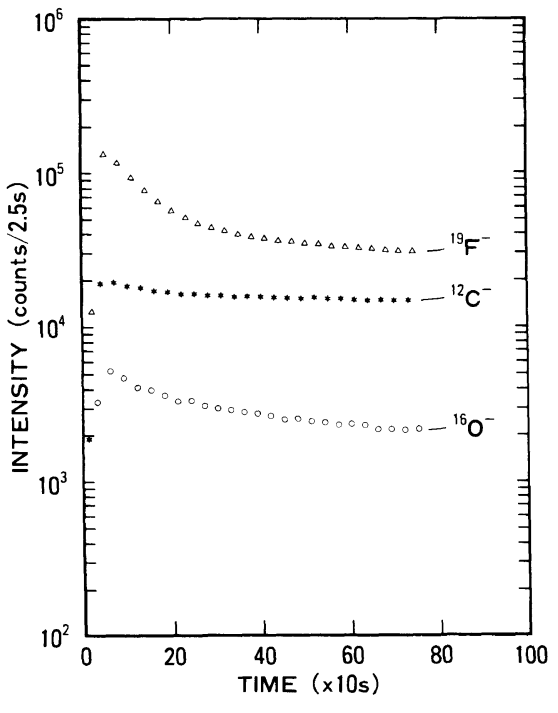

Figure 2. Depth profiling of the polymer blend between PVDF and PMMA (50/50 v/v).
(FVDF) is miscible with poly(methyl methacrylate) (PMMA). SIMS depth profiling was done for the blends of PVDF and PMMA $(50 / 50 \mathrm{v} / \mathrm{v})$ making use of the time dependence of the intensities of secondary ${ }^{12} \mathrm{C}^{-},{ }^{16} \mathrm{O}^{-}$, and ${ }^{19} \mathrm{~F}^{-}$ions. "Time" means the time of measurement from the start. By the bombardment of primary ions, crator was produced on the sample surface, the depth of which increases with increase of the time. If the depth is, therefore, proportional to the time, the time dependence should be equivalent to the depth dependence. In the plasma etching of polymeric materials including PVDF and copolymer of MMA and methacrylic acid linear relationships were found between the etch depth and the time except for induction period. ${ }^{9}$ This is one support to the above equivalency. The other support is the constant intensity of ${ }^{12} \mathrm{C}^{-}$ irrespective of time. In Figure 2 is shown the SIMS depth profiling of a blend. Intensity of ${ }^{12} \mathrm{C}^{-}$is almost kept at constant except for the region close to the surface.

Intensity of ${ }^{19} \mathrm{~F}^{-}$decreases rapidly from the surface to the inside. It means PVDF is more abundantly distributed in the surface than in the inside. Intensity of ${ }^{16} \mathrm{O}^{-}$also decreases from the surface to the inside. However, this is not due to abundant distribution of PMMA in the surface, but to an existence of oxidized compounds in the surface. This statement will be confirmed in the next section. In the thermodynamics of polymer blends the solubility parameter is the most important parameter describing the miscibility between component polymers. However, this parameter is insuf- 
ficient to explain the above finding. The samples were prepared in the form of film by casting from dimethyl formamide (DMF) solution. The values of solubility parameters are 14.7, 18.93, and $24.8 \times 10^{3} \mathrm{~J}^{-1 / 2} \mathrm{~m}^{-3 / 2}$ for FVDF, PMMA, and DMF, respectively. ${ }^{10}$ Therefore, if the solubility parameter is the good parameter describing the concentration gradient, PMMA should be much abundantly distributed in the surface in which the concentration of PMMA becomes larger during the evaporation of solvent. Instead, the surface tension is the best parmeter describing the gradient. The values of surface tension are 25 and $39 \times 10^{-3} \mathrm{Nm}^{-1}$ for PVDF and PMMA, respectively.11 Besides the solubility parameter, a new parameter, surface tension must be introduced as a parameter describing the concentration gradient in polymer blends. ${ }^{1}$ Similar finding has been done in the XPS depth profiling for the diblock polymers between polystyrene and poly (ethylene oxide).12 Furthermore, structure factor was also studied for the blends of PVDF and PMMA. ${ }^{13}$ In this study the structure factor is always larger in the blends than in homopolymers. This means there are concentration gradients in the blends. The origin of these gradients was clarified by our depth profiling.

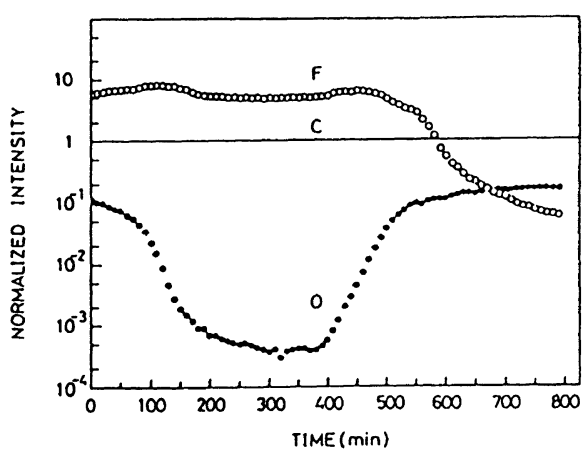

Figure 3. Depth profiling of the optical fiber composed of PVDF (clad) and PMMA (core) normalized with the intensity of ${ }^{12} \mathrm{C}^{-}$.

\section{OPTICAL FIBERS}

Optical fibers are, at least, compsosed of two components in order to accomplich total reflection of optical rays. SIMS depth profiling is promising to analyze the two-component structures. The profiling was done for the optical fibers composed of PVDF (clad) and PMMA (core). ${ }^{2}$ Similar to the last section, the intensities of ${ }^{12} \mathrm{C}^{-},{ }^{16} \mathrm{O}^{-}$and 
${ }^{19} \mathrm{~F}^{-}$ions were used for the profiling. Results were shown in Figure after normalizing by the intensity of ${ }^{12} \mathrm{C}^{-} \cdot{ }^{2}$ In the former half in the time domain, the intensity of ${ }^{19} \mathrm{~F}^{-}$was almost constant and very large; this means the clad is actually composed of PVDF. In the latter half, the intensity of ${ }^{16} \mathrm{O}^{-}$behaved similarly suggesting the existence of $\mathrm{PMMA}$ in the core. Furthermore, in the very early former part ${ }^{16} \mathrm{O}^{-}$ was intense. This reflects an existence of oxidized componds. $\mathrm{C}-\mathrm{F}$ bonds are easily degraded compared with other kinds of bond. It implies the possibility of the observation of carbonization process instead of depth profiling in the last section. The constancy of ${ }^{19} \mathrm{~F}^{-}$intensity in Figure 2 liberates us from such an implication. The large intensities in the very early stage both in Figures 1 and 2 support the statement in the last section: the existence of oxidized compounds in the surface.

\section{VIDEO TAPES}

Video tapes are conposite materials composed of polymeric base films and magnetics. In order to know the concentration gradients, four kinds of video tapes of the grade of
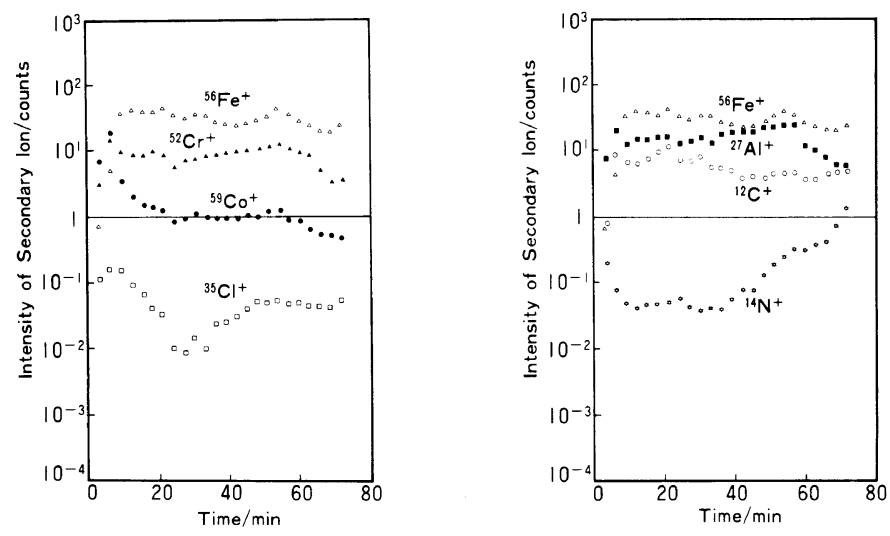

Figure 4. Depth profiling of the video tape A normalized with intensity of ${ }^{16} \mathrm{O}^{+}$. 
T-120 were profiled making use of the intensities of ${ }^{12} \mathrm{C}^{+}$, ${ }^{16} \mathrm{O}^{+},{ }^{27} \mathrm{Al}^{+},{ }^{35} \mathrm{Cl}^{+},{ }^{52} \mathrm{Cr}^{+},{ }^{56} \mathrm{Fe}^{+}$, and ${ }^{59} \mathrm{Co}^{+}$ions. In Figure 4 is shown the profiling of the sample $A(3)$. In order to avoid the confusion due to the crowdness of experimental points, figure was divided into (a) and (b), in which the intensities of ${ }^{35} \mathrm{Cl}^{+},{ }^{52} \mathrm{Cr}^{+},{ }^{56} \mathrm{Fe}^{+}$, and ${ }^{59} \mathrm{Co}^{+}$were compiled in (a), while ${ }^{12} \mathrm{C}^{+},{ }^{14} \mathrm{~N}^{+},{ }^{27} \mathrm{Al}^{+}$, and ${ }^{56} \mathrm{Fe}^{+}$were in (b). For the convenience of comparison, intensities of ${ }^{56} \mathrm{Fe}^{+}$were compiled both in (a) and in (b). Intensities of secondary ions are much enhanced by the existence of wxygen. ${ }^{14}$ This phenomenon is known as wxygen effect. In order to remove this wxygen effect, all intensities of the secondary ions were normalized by the intensities of ${ }^{16} \mathrm{O}^{+}$in Figure 3 . Comparing with the profiling patterns between four samples, we found some differences between them (differences due to the differences of manufacturing companies). Generally speaking, the samples $A$ and $D$ (the profiling patterns are not shown here for the samples $B, C$, and D) are close with each other, and $\mathrm{B}$ and $\mathrm{C}$ are. More precisely,

1) $\mathrm{Cl}$ is more abundantly distributed in the region close to the magnetics in the sample $A$. This trend is explainable with a term of the distribution of antistatic agent which includes $\mathrm{Cl}$.

2) Cl is more abundantly distributed in the opposite side (base film) in the samples $B$ and $C$, while $C l$ is in both sides in the sample $D$.

3) The time required for the depth profiling over total thichness is the shortest in the sample $A$ in spite of almost equal thickness in these four samples. This finding is explainable with a term of the effectiveness of the antistatic agent. 4) Metallic elements, $\mathrm{Al}, \mathrm{Fe}, \mathrm{Cr}$, and Co are localized in the area close to the surface (magnetics) in the samples $A$ and $D$, while they are almost equally distributed in the whole renge of the samples $B$ and $C$. A small amount of these elements is observed even in the inside of base film in the samples $A$ and D. It is still unclear whether these traces are due to actual migration to inside or poor resolution in the measure- 
ments.

5) An increase of $\mathrm{N}$ is observed corresponding to the decrease of the above metallic elements in the inside of the whole samples.

6) Among physical properties, both of static and dynamic friction constants are not correlated with any finding from the SIMS depth profiling.

7) Dynamic resistance is well correlated with the intensity of $\mathrm{Cl}$ in the region close to the surface.

From the above-mentioned four examples, readers can find SIMS depth profiling is a promising technique in the characterizetion of polymeric materials having concentration gradient.

\section{REFERENCES}

1. R. Chûjô, T. Nishi, Y. Sumi, H. Naitoh and

H. Frenzel, Polym. Lett., 21, 487 (1983)

2. R. Chûjô, T. Nishi, Y. Adachi, H. Naitoh and

H. Frenzel "Secondary Ion Mass Spectrometry, SIMS IV", Springer-Verlag, Berlin, 1984

3. R. Chûjô, T. Nishi, H. Naitoh and T. Adachi, Bull. Inst. Chem. Res. Kyoto Univ., 66, 312 (1988)

4. A.J. Rudge, Brit. Pat., 710523 (1954)

5. D.T. Clark, W.J. Feast, W.K.R. Musgrave, and I. Ritchie, J. Polym. Sci., Chem., 13, 857 (1975)

6. D.M. Buck, P.D. Marsh, F.A. Milcetich, and K.J. Kallish, Plast. Eng. No. 4, 33 (1986)

7. R. Chûjô and M. Wada unpublished work (1989)

8. P.V. Danckwerts, Trans. Faraday Soc., 46, 300 (1950)

9. L.A. Pedersen, J. Electrochem. Soc., 129, 205 (1982)

10. P.A. Small, J. Appl. Chem., 3, 71 (1953)

11. W.A. Zisman "Adhesion and Cohesion", Elsevier, 
SIMS Depth Profiling of Polymer Surfaces

Amsterdam, 1962

12. H.R. Thomas and J.J. O'Malley, Macromolecules, $\underline{12}, 323$ (1979)

13. J.M. Wendorff, Polym. Lett., 18, 439 (1980)

14. A. Benninghoven, Surf. Sci. 53, 596 (1975) 